\title{
CONCEPTUAL FRAMEWORKS FOR FIRM STRATEGY: An Information Systems Perspective
}

\author{
Rafael Andreu I Civit \\ PROFESOR ORDINARIO DE \\ SISTEMAS DE INFORMACIÓN Y DIRECCIÓN GENERAL, IESE \\ Kety Jáuregui \\ DiRECTORA ASOCIADA DEL PROGRAMA DOCTORAL ESADE-ESAN
}

\begin{abstract}
Resumen
El concepto de estrategia y formación de estrategia puede ser analizado desde diferentes perspectivas. Mintzberg (1990) ha identificado diez escuelas básicas de pensamiento con relación a este tema. La estrategia es concebida como un proceso de visión, diseño, planeamiento o posicionamiento; como un proceso de conocimiento o aprendizaje, sujeto a influencias políticas, culturales o ambientales, o más propiamente como un proceso centrado en la transformación. A través de los años, los sistemas de información han venido a jugar un papel crecientemente estratégico en los negocios, capaz de apoyar la formulación e implementación de estrategias y, particularmente, la reformulación de estrategias. Este trabajo ofrece una revisión de la literatura sobre el tema y relaciona los sistemas de información con las diez escuelas de estrategia mencionadas, permitiendo la discusión de la utilidad de los diferentes tipos de sistemas de información.
\end{abstract}

\section{Introduction}

Nowadays, firms are facing ever-increasing risks and opportunities created by a set of distinct but interrelated factors: a changing environment, fierce competition, industry liberalization and the emergence of a global economy. In order to survive and compete effectively, firms must develop a flexible outlook; in other words, they must formulate and/or re-formulate their strategies, design and deploy appropriate organisational structures, and be prepared to operate in an evolutionary mode.

The strategy concept and the strategy formation process can be approached from different perspectives, covering all of the firm's activities. Authors in the general management field have given different definitions of strategy, emphasising, among others, the following aspects: strategy as a means to attain competitive ad- 
vantage; strategy as a means to achieve the organisation's vision, mission or objectives as defined by the firm's leaders, etc. Mintzberg (1990) has suggested that these approaches can be grouped in ten schools of thought. These schools variously conceive of strategy as a process of vision, design, planning, positioning; or as a process of cognition or learning, subject to political, cultural, or environmental influences; or more particularly as a process centred on transformation. Some of these schools propose descriptive conceptual frameworks, while others are prescriptive.

Over the years, Information Systems (IS) has evolved in its organisational role. Currently, IS has a strategic role, with the potential to affect business operations and industry reconfigurations, and so influence competition. For example, IS can have a great impact on cost or differentiation when used in value chain activities (Porter, 1980). From another perspective, IS can be seen as a unique and valuable «resource» that adds value to the firm's activities (an illustrative and classic example is that of SABRE - American Airlines Reservation System).

IS researchers have proposed several conceptual frameworks to support the formulation, re-formulation and implementation of a firm's strategy. For example, the evolution of IS in organisations, and conceptual frameworks that help firms to identify their critical IS. In general, the question of how IS can be integrated with strategy has been studied from two points of view: (1) IS as a set of data and information flows that are necessary for the firm's information functions and processes in accordance with its strategy (in other words, as a set of applications that give support to the firm's information needs); and (2) IS with an emphasis on technological considerations, especially on new technologies that may impact the business's development.

As strategy is approached from different standpoints, its link with IS is not trivial. It is rather a complex issue because of the diverse interrelations that exist and that can be exploited. Research on this topic began at the end of the '70s and underwent a boom at the beginning of the '90s. This paper gives an overview of the literature on IS strategy and how IS relates to the different schools of thought in strategy research, with the aim of proposing ways of integrating IS in each strategy school. The paper is organised around the ten strategy schools proposed by Mintzberg (1990), as follows: first, for each school, the most relevant ideas about strategy are described; then, ideas for integrating IS and strategy are reviewed and discussed.

\section{The Design School: Strategy formation as a process of conception}

This school was the first to consider strategy in a competitive context. It proposes a model and guidelines (or prescriptions) for formulating a strategy. The model comprises two interdependent activities: strategy formulation and strategy implementation.

Strategy formulation is broken down into three steps: environmental analysis, internal analysis, and target and objective setting based on the firm's capabilities. In the environmental analysis step, opportunities and threats (or risks) are identified. In internal analysis, the firm's strengths 
and weaknesses are assessed. The aim is to match opportunities with the firm's capabilities, particularly its distinctive capabilities (i.e., those in which it performs well and that are difficult for others to imitate), so as to minimise the impact of its weaknesses and maximise the contribution of its strengths. This is what is referred to as SWOT (strengths, weaknesses, opportunities and threats) analysis.

Strategy implementation involves designing the organisational structures, incentive and control systems and other management systems (often implicitly including IS), and their interrelationships, in such a way as to make the strategy work. In this process, IS is normally included in the form of the information flows that are needed for the organisational structures and systems to work effectively. Information flows through all organisational levels are vital to ensure that the organisation's members are informed about goals and actual accomplishments (the control issue), and also to coordinate their tasks.

\section{Strategy and Information Systems}

IS can be integrated with business strategy if IS/IT issues are taken into account during both the strategy formulation and the strategy implementation steps. IS/IT can help to identify areas in which sustainable competitive advantages could be achieved (Parsons, 1983; McFarlan, 1984; Benjamin, R.I, Rockart, J.F, Scott Morton, \& Wyman, J, 1984). IS are seen as providing the elements (data, processes, information) with which the organisational structure operates. Also, IS are seen as the basis on which control can be exercised in the organisation.
Normally, in this school, as mentioned above, IS are considered at strategy implementation time. In the early '70s, IS were used to support administrative and control tasks, especially tedious and routine tasks such as accounting, payroll and inventory control. IT was understood only in terms of machines with great data-processing speed. In this context, research focused on studying and explaining the use and performance of IS in organisations, as well as how to effectively manage the IS department, conceived mainly as a technical department. Also, the Management Information Systems (MIS) and Management Decision Systems (MDS) concepts were developed, and their design and construction issues were considered. Gorry \& Scott Morton (1971) focus on the development of IS from the perspective of the organisation's decision levels. Hence, IS will support (structured or nonstructured) decision-making in the organisation and will provide the means by which the organisational structure operates. Consequently, IS improve organisational effectiveness and efficiency and enhance the productivity of knowledge work.

\section{The Planning School: Strategy formation as a formal process}

This school considers strategy formulation as a formal planning process which is highly systematised and rational and has a long-term outlook. Planning consists of identifying a desirable future and deciding how to achieve it. The planning process comprises plan formulation, implementation, review and evaluation. The formulation stage is divided into strategic plans, medium-term programmes, and short-term detailed plans and budgets 
(Steiner, 1979). Implementation consists of the deployment of short-term plans and includes the organisational structure and control systems.

In this school, IS are considered a necessary tool to obtain the information that is needed for formal planning. Information about the firm's past performance (sales, earnings, return on investment, market share, etc.) is essential for forecasting, identifying alternative courses of action and evaluating them.

\section{Strategy and Information Systems}

In this school, the integration of IS with business strategy can be approached from two different perspectives: 1) IS/IT to support plan development and implementation; 2) strategic planning of the IS functional area.

The first includes IS/IT-based tools to help top management in business planning, such as modules to support internal and external analysis, simulations, etc.

In contrast, IS strategic planning at the functional level is aimed at helping to improve the effectiveness of IS in the firm. For example, Nolan (1979) and Rockart (1979) have published studies on some IS planning topics; IBM approached the design of IS after the business strategy planning; and Andreu, Ricart \& Valor (1992) have proposed a global focus on IS planning, in parallel with the business strategy.

The growth stages model proposed by Nolan (1979) and its later refinements are conceptual frameworks of the process whereby IS evolve in the organisation. These frameworks are useful for designing the functional strategy of IS, as a di- agnostic tool, because they help to judge the organisation's position with regard to the introduction and assimilation of new information technology, and therefore, direct its growth.

The CSFs proposed by Rockart (1979) are defined as the few key areas in which things must go right for the organisation to prosper. These areas are usually few and any executive must identify, measure and control (monitor and improve) them with constant attention. CSF analysis is used mainly to help executives determine their information needs for control purposes. Consequently, it helps companies identify the information systems they need to develop. It can also be used to identify executive information systems opportunities.

The Business Systems Planning (BSP) methodology, developed by IBM, is designed to determine IS/IT needs based on business processes. In general, planning consists of: (1) defining the company's business processes; (2) defining a portfolio of future IS applications, i.e. the firm's information needs and priorities; and (3) defining the technology and constructing the infrastructure to implement IS development. IS/IT applications that satisfy the firm's information needs are obtained by following these steps.

The methodology presented by Andreu, Ricart \& Valor (1992) consists of presenting a set of generic strategic actions (ITSGA). These are information technology applications with general potential to improve business strategy, in such a way that the strategy contains IS/IT components that can contribute to the attainment of sustainable competitive advantages. For instance, some of the product-related ITSGAs focus on increasing the products' 
information content, personalising the product or creating new products.

\section{The Positioning School: Strategy formation as an analytical process}

This school, like the design and planning school, is prescriptive. It regards competitive strategy as the search for a favourable competitive position in an industry.

The conceptual framework focuses on an analysis of the firm's market environment, with an emphasis on industry structure and competition, in order to select a strategy that will lead to competitive advantage (Porter, 1980). The analysis of industry structure consists of studying the structural factors in detail (intensity of rivalry among competitors, threat of new entrants, threat of substitutes, buyers' and suppliers' bargaining power), so as to identify the critical drivers of long-term profitability and the industry's attractiveness (Porter, 1980). Other important concepts in this model are those of the value chain and generic strategies. The value chain is a framework that helps conduct the firm's internal analysis, studying all of the firm's activities in a global way, so as to determine the types of activities and processes that create value for the customer. Generic strategies represent alternative ways of competing (cost leadership, focus, and differentiation or high segmentation).

Another important point examined by this school of thought is technology as a source of competitive advantage. Technology (which includes information systems and everything to do with technological change) can be an important driver in an industry's general structure if it is used intensively in value chain activities (Porter, 1985).

\section{Strategy and Information Systems}

In this school, IS have been considered mainly insofar as they directly affect the firm's competitive position. For instance, IS can help to establish entry barriers and/ or develop substitute products or services. For example, automatic tellers have limited the establishment of new «bank branches» in the bank industry, and electronic mail has become a substitute for regular mail (Parsons, 1983).

IS can help firms beat their competitors in different ways. It may help them to develop new products or markets at lower cost than competitors, or establish agreements with suppliers and customers that will tie customers to the firm's products and suppliers to a strict delivery timetable. Consequently, IS and technological trends should be considered important elements of industry analysis (e.g., Internet use, e-commerce, etc.) because they can be a source of competitive advantage for the firm.

Within the firm's value chain, IS is considered a support activity, part of the infrastructure (Porter, 1980; Porter \& Millar, 1985). All primary and support activities in the value chain require ISbased support because all of them require and generate information.

In this context, the integration of IS and strategy can be viewed from either perspective: external analysis (industry structure) or internal analysis (value chain). The aim is to identify opportunities for IS-based competitive advantage. The most important models developed by 
IS researchers who use some of this school's ideas include: McFarlan, Mc Kenney \& Pyburn's (1983) strategic grid; McFarlan's (1984) five questions; Wiseman's (1988) strategic option generator; and Rayport \& Sviokla's (1995) virtual value chain.

The strategic grid is a very useful diagnostic tool for positioning (in the socalled «support», «turnaround», «factory» or «strategic» cells) a firm or a business unit according to the strategic impact that IS has on it. IS/IT can play very different roles in different firms. For some, it performs essentially operational functions, while for others it may cover an area of strategic importance.

Another tool for analysing the strategic impact of a firm's IS is McFarlan's (1984) «five questions». Companies can identify opportunites for IS-based competitive advantage by asking questions such as: Can IS technology build barriers to entry? Can IS technology build in switching costs for customers? Can technology change the basis for competition? Can IS change the balance of power in supplier relationships?

Similarly, the «strategic option generator» (SOG) model is designed to help identify IS opportunities that will enable the firm to achieve competitive advantage. It focuses on the way IS is related to five strategic thrusts (differentiation, costs, innovation, growth and alliances) and three strategic objectives (supplier, customer and competitor). Thus, SOG identifies 15 areas of opportunities for generic strategies and each area is open to the perspective of the top managers' vision.
Finally, Rayport \& Sviokla (1995) expand Porter's work and classify the value chain into two types: physical and virtual. They consider that any business competes in two worlds: a) a physical market (the marketplace); and b) a virtual world made up of information (the market space or electronic market). In the physical value chain, information is considered as a support element that adds value to line activities. In the virtual value chain, information is the source of value itself.

\section{The Entrepreneurial School: Strategy formation as a visionary process}

From this section on, all the strategy schools of thought (the entrepreneurial school, the cognitive school, the learning school, the power school, the cultural school, the environmental school and the configuration school) are descriptive rather than prescriptive. These schools are more interested in how the strategy is actually formed -how it is developed-at both the individual and the organisational level, and less so in prescribing concepts and procedures for formulating it.

In the entrepreneurial school, strategy formulation is considered as the result of the leader's vision. In a global sense, the vision is a subjective idea of how the leader «sees» his business in the future. This vision is based upon knowledge of the business and the leader's individual capabilities (such as intuition, creativity, judgement, wisdom, experience).

The firm's strategy responds to the leader's initiatives; therefore, a firm's leader is key for organisational success. 


\section{Strategy and Information Systems}

Strategy formation is described as a visionary process rooted in the leader's experience and intuition. Consequently, the entrepreurial school focuses on personal issues. In this context, integrating IS and strategy is not easy.

IS can contribute to the subjective strategy construction process by delivering internal and external information in an orderly fashion, and by facilitating data presentation through graphs or other convenient ways, much in the tradition of executive information systems (EIS).

EIS can also include support systems for decision-making (Turban 1988; Watson Hugh, Rainer Kelly \& Koh Chang, 1991). These systems are highly personalised and present information in the manner each individual executive prefers, although some standards may be employed.

\section{The Cognitive School: Strategy formation as a mental process}

This school considers strategy as a construct that is created in the mind of the strategist. It focuses on the mental activities related to the strategy-making process. Mintzberg (1990) states that there are five relevant approaches for explaining the phenomena associated with problem-solving and strategic decision-making. They are: Cognition as confusion (people have very limited capacity to receive and process information); cognition as information processing (attention, encoding, storage/retrieval and retrieval); cognition as a mental mapping (an organised body of knowledge that explains how things work); cognition as concept acquisition (how the strategy manages to be formed); and cognition as a constructive model (how each strategist constructs his own understanding by taking information from the environment and processing it in a unique way, subjectivity being an important factor).

\section{Strategy and Information Systems}

In the cognitive school, IS/IT cannot in principle contribute significantly to any of the approaches described by Mintzberg (1990). However, IS/IT can sometimes contribute in surprising ways. For instance, in the first and second approaches, where strategists are assumed to be «information workers», IS/IT can support the activities that involve absorbing, processing and disseminating information about issues, opportunities and decisionmaking in a precise and rapid way. In the tradition of «Decision Support Systems» (DSS) at the individual level and «Group Decision Support Systems» (GDSS) at the group level, it can provide support systems for decision-making.

A DSS is a system that facilitates structured and non-structured problem-solving, as it combines data, analytical models and friendly software in a single interactive, computer-based system (Sprague, 1980). It should be stressed that a DSS gives the decision-maker (in this case, the strategist) access to data and models, but it is the decision-maker who supplies the intelligence, intuition and judgement for problem-solving. 


\section{The Learning School: Strategy formation as an emergent process}

The learning school was initiated as a reaction to (and a questioning of) the planning school. The approach it adopts is fairly rational (attainment of pre-determined and precisely defined objectives, and a highly formalised organisational structure). The fact that the strategy can originate within the organisation without any logical or sequential planning is ignored.

Strategy is understood as a pattern in an action flow (Mintzberg \& Waters, 1985). This pattern is said to arise from the firm's historical decisions, but bearing the future in mind. It emerges in small steps and is based on continuity as the organisation adapts over time. Learning occurs by doing» and requires both time and resources. Observation of past behaviour is the basis for strategy development, without taking into account whether such behaviour was intentional (planned) or not. Consequently, strategy can only be made explicit ex-post.

In addition, the adherents of this school point out that in a complex and dynamic world, the strategy that is actually carried out (the realised strategy) contains a large element of emergent strategy. This is so because it has to be open, sensitive and flexible (willing to learn) in order to respond to changing events.

Recent additions to this school include interpretations of strategy formation from a capability standpoint and from a knowledge development perspective. Capabilities and knowledge are considered as the main results of the learning process, both in the individual and in the organisation. Strategy formation is represented as a col- lective learning process (organisational learning).

From a capability perspective, strategy consists of developing difficult-to-imitate organisational routines, whose purpose is to coordinate the firm's resources so as to render their use as productive as possible, thus constituting a source of distinctive competencies. Capabilities are also considered the result of the organisation's practice (using its organisational structure and management systems).

\section{Strategy and Information Systems}

IS can support organisational learning to the extent that it reflects a way of doing things that is specific to the organisation. IS may include organisational routines (information flows, calculations, ways of interacting, cooperating and making decisions, as long as the corresponding processes are well structured) generated through interaction between IS users (who in the process make their knowledge and experience explicit) and the IS staff. As IS are constantly evolving (new functions being added to them over time in an incremental way), they can foster the development of the organisation's capabilities.

According to this school, no matter how innovative IT may be, it will not, by itself, create any competitive advantage -rather, advantage will be achieved by putting organisational knowledge, experience and capabilities, enabled by IS/IT, to work (Andreu \& Ciborra, 1996). In other words, IT/IS can add value to a firm only as a tool and infrastructure that enables the efficient and effective pursuit of the learning organisation concept (King, 1996). For instance, Groupware technologies can support communication activi- 
ties and collaborative work as an infrastructure, creating shared spaces where workers can coordinate their activities efficiently and, up to a point, independently of time and space constraints.

\section{The Power School: Strategy formation as a process of negotiation}

The power school's assumption is that when there is disagreement over goals or over the preferred means for pursuing goals, strategic decision-making will be affected by power and politics. The disagreements and conflicting interests that are built into any organisation represent an opportunity for negotiation and re-negotiation. In this context, strategy formation is conceived as a negotiation process that can take place at the individual, departmental or divisional level (that is to say, within the organisation) and at the organisational level (the organisation's behaviour in response to its environment).

The strategy that results from situations within the organisation can be considered an emergent process (Mintzberg, 1990). Strategy is seen as a political game in which it is very important to determine the context in which the game takes place and identify the players. Pfeffer (1992) stresses that it is essential to know the sources of power and to be able to counterbalance the power of other participants in the game, including potential allies and possible opponents.

\section{Strategy and Information Systems}

IS can help to rationalise work, support decision-making and communication, and improve internal and external coordination. It can also support the distribution of power. In this sense, IS can be seen as a means of bringing about a change in the balance of power within the organisation.

Similarly, an organization's IS define a pre-determined information distribution pattern, as they are part of the organisation's formal structure. This results in some people or groups having more access to information than others, thus helping to define power arrangements.

Moreover, IS can help members of different groups within the organisation enhance their control or reduce their dependency. For instance, people who depend on other individuals can become less dependent if they have IS that support them in problem-solving or critical contingencies; as a result, they gain power. It is stressed that the ability to create dependency is one of the most important determinants of power.

In a study conducted by Markus (1983), it was found that when a new IS is implemented, a process of power dynamics is triggered. Certain design features in an IS may imply a division of roles and responsibilities that alters the status quo within the organisation. This alteration is likely to generate resistance/support in the social context in which the system is implemented (where different IS interact). In other words, individuals or groups that stand to lose power will resist the change, while those who gain power will support it.

\section{The Culture School: Strategy formation as a collective process}

This school considers that firms have their own organisational experience, gained over time, as a result of which managers 
have a set of tacitly assumed rules in mind so that they are able to perceive a situation and react to it according to the «organisation's own» conceptual frameworks and paradigms. In other words, it is based on the social force of culture as a means of building the strategy. Therefore, strategy formation is seen as a process of collective and cooperative vision, based on a pattern of basic assumptions shared by the organisation's members.

Putting organisational culture at the basis of strategy makes sense because values, beliefs, assumptions and symbols that are shared by an organisation's members meet the conditions for creating competitive advantages. A firm's organizational culture can be defined as the way in which it conducts its business (Barney, 1986). Often, a firm's organisational culture has three attributes: it is valuable, rare and imperfectly imitable, which means it can provide sustainable competitive advantage in a given context (Barney, 1986). A culture tends to be valuable because it fosters the organisation's ability to do things and behave in an idiosyncratic way, so as to add financial value (high sales, low costs, high margins) to the firm. It is rare to the extent that its attributes and characteristics are hard to find in other firms' cultures. And it is imperfectly imitable when it is difficult to replicate because its values, symbols and beliefs, its history and heritage cannot be readily described and categorised. If a firm's culture is valuable and rare but not impossible to imitate, it will not be a source of sustainable competitive advantage.

In addition, organisational culture provides the organisation with a context in which strategy can unfold effectively. Organisational culture is considered to have a strong tacit knowledge component, as it originates in a process of socialisation.

\section{Strategy and Information Systems}

Integrating IS in a firm's organisational culture is very difficult. Among other reasons, this is so because often managers and the information systems community have different and even opposite assumptions and beliefs.

Schein (1997) presents these two communities as sub-cultures in collision. Each has a different approach to information, people, organisations and managerial work. For instance, with respect to information, the information systems community may seek to run a paperless office, while managers may prefer to get information from people rather than from computers (Davenport, 1994). With respect to people, the IS community tends to assume that IS/IT lead and people follow, while managers tend to think the opposite, that technology should adapt to people.

Schein (1997) stresses that to unite these two sub-cultures they need to carry out joint tasks, so that learning can occur and new assumptions can be created to combine the best elements of each.

Other authors argue that the use of new information technology to support managerial and professional work will affect organisational culture. In other words, it will drive cultural, and consequently organisational change: for instance, less use of face-to-face communication for office work, or remote or virtual teamwork for tasks that were impossible to coordinate before (because computer messaging is faster, traceable, and accessible from almost anywhere). 


\section{The Environmental School: Strategy formation as a reactive process}

This school's basic concept is that the environment conditions and influences the organisation. The environment is seen as being made up of different domains -social, cultural, legal, political, economic, technological and physical- which are interdependent (Hatch, 1997). While other schools consider the environment as merely a factor, here it plays a leading role: the organisation is seen as an open system.

According to this school, strategy formation takes place as a passive process in response to environmental conditions. There are three lines of thought in this school: contingency theory, population ecology, and the institutional approach.

Contingency theory states that the most effective way to organize depends on the environment (its complexity, stability, market diversity and hostility). Based on these conditioning aspects, the organisation will outline a set of responses.

In the '70s, a second approach, called population ecology, emerged. It sees the environment as the agent that naturally selects the organisational forms that are best adapted to its characteristics. Thus, some survive and others are eliminated. The basic assumption is that organisations compete within their corresponding ecological niches for the resources they need in order to operate. Also, organisations adopt patterns of interdependence within the group (or population) that affect each member's survival and prosperity.

Lastly, the institutional approach considers the organisation as an organic whole embedded in social reality. Not only do organisations require raw materials, capital, labour, knowledge and equipment; they also need the acceptance of the society in which they operate (Hatch, 1997). In other words, social legitimacy (made up of the social, cultural, political and legal sectors) is seen as a major environmental force.

\section{Strategy and Information Systems}

As we have seen, this school's emphasis is on environmental analysis. The environment interacts with and influences the organisation, creating opportunities and imposing restrictions for the organization's survival and forcing it to adapt. Firms must respond to these changes by designing organisations that are appropriate for the given level of environmental uncertainty and complexity. From this perspective, advances in technology, particularly in IS/IT, can lead to changes in organisations' environments.

Technology can create or support substitute products or options for alternative services. It can also make «today's» products obsolete «in the future».

Technological progress has led to a merging of information technology and telecommunications that has had a great impact on organisations and has restructured entire industries, such as financial services (automatic cash dispenser machines), manufacturing (CAD/CAM), or retailing (POS) (Bradley Stephen, Hausman Jerry and Nolan Richard, 1993). The Internet is stimulating new ways of running businesses electronically, and thus restructuring businesses again; for example, in the area of financial services (home banking). 
Technological evolution has been a catalyst of social change. The information age has witnessed great social, cultural, legal, political and economic changes. The use of credit cards, for instance, serves to illustrate many aspects of contemporary society: most people, including young people, use credit cards for their bank transactions and to buy on credit. This implies a change in people's ideology, habits and norms, which in turn requires a response from firms in terms of the way they define and implement their strategy.

\section{The Configuration School: Strategy formation as a process of transformation}

The main message of the configuration school is that strategy formation is an episode-based process involving two basic principles: configuration and transformation. While configuration describes the firm's state (the organisation and its context), transformation describes the strategy formation (creation) process. Transformation occurs when the firm's configuration gets out of synch with its environment, so that it needs to be resynchronized. Successive configurations and transformations define the «life» of a firm over time (for example, the life cycles of organisations). The key is to maintain stability and acknowledge the need for transformation, while adapting to the context (Mintzberg, 1998).

An organisation can be described as a stable configuration -a particular organisational design linked to a particular type of context at a given moment in timewhich can be interrupted by strategic change (transformation).
Transformation consists of a very short process of transition from one configuration to another. In other words, transformation may set out to change the organization in accordance with the direction in which it is heading and thus put it on a stable course (new configuration). Although the concept of change is very broad, this school sees it as the transformation of many elements at the same time (revolutionary change). This type of change occurs only rarely during a firm's life.

Mintzberg (1998) maintains that the transformation process can be based on any of the other schools of thought (design, cognitive or planning, among others), but the way it is applied will depend on context and time. For instance, for long periods and simple, stable environments, the planning school and a bureaucratic organisation can be used.

\section{Strategy and Information Systems}

Bearing in mind that the configuration school concentrates on two key elements, namely configuration and transformation, the integration of IS and strategy can be analysed by relating the contextual dimension to configuration. IS can play a key role in organisational forms because it facilitates work coordination and the organisation of the firm's members (Galbraith, J.R.; Lawler III E.E. (1993). As Malone (1987) remarks, the use of IT in the design of organisations can help to reduce coordination costs.

Coordination is an important aspect of organisational design because in complex and dynamic environments the organisation must be capable of integrating all its activities in a coherent whole in order to 
respond rapidly, with quality and low cost. Moreover, in dynamic environments organisations tend to opt for a greater degree of decentralisation, with a flatter structure, less hierarchy, greater decision autonomy and hence greater delegation; to make this possible, coordination mechanisms need to be built into the organisational structure. In this context, IS can facilitate good coordination through better information flows (moving information in multiple directions) both within firms between firms and their environment.

Henderson \& Venkatraman (1994) and Earl (1996) have contributed studies on IS strategy using ideas related to the configuration school. They focus on the IS strategy model from an organisational transformation perspective, understanding strategic alignment as a dynamic process.

Henderson \& Venkatraman (1994) propose a strategic alignment model for formulating and implementing IS strategy. The model is based on two fundamental strategy concepts: (1) the strategic fit between the firm's external and internal components; and (2) functional integration (the relationship between IS/IT and the business). The authors define the model in four domains: business strategy, IT strategy, organisational infrastructure and processes, and IS infrastructure and processes. Alignment is seen as a process of continuous adaptation and change; therefore, there are various alignment perspectives. The interrelation of the four domains produces four alignment perspectives: strategy execution, technology transformation, competitive potential and service level. The authors state that none of these four domains is the best one for carrying out the strategy because it all depends on time and context. Also, the potential im- pact of IS/IT on the business is so varied and complex that executives should consider these alignment perspectives as conceptual frameworks and be ready to continuously adapt them. Furthermore, the purpose of the model is to provide a set of ideas and tools to leverage the emerging capabilities of IT for transforming organisations and markets (Henderson \& Venkatraman, 1994).

Earl's (1996) IS/IT alignment model is based on the integration of four domains: IS strategy, IT strategy, management information strategy and the organisation's strategy. The purpose of the model is to integrate information resources within the organisation, and thus provide a managerial checklist for the Chief Information Officer (CIO). To make this perspective succeed, it is important to identify the specific role of the CIO.

\section{Conclusion}

As we have seen throughout this paper, integrating IS and business strategy is a complex process because there are multiple relationships between strategy and IS, and above all because these interrelationships are dynamic (they change over time).

Placing IS in the context of different strategy schools of thought has enabled us to order and analyse the different IS models and tools as they relate to strategy. These categories should be used as building blocks for the firm's information systems strategy. The idea is to integrate IS issues from each school according to each firm's strategic considerations. Usually, when a firm's strategy and IS strategy are formulated and implemented, elements of 
one or more schools of thought (for example, mental and social aspects, the demands of the environment, or organisational learning) will be taken into account. The exact combination of components will depend on the context the firm finds itself in at that particular moment. In dynamic and complex environments, for example, the firm's formulation and implementation of its IS and strategy may include aspects of the entrepreneurial, power, positioning and cognitive learning schools; whilst in a stable environment, the planning, design and positioning schools are likely to be more relevant.

This analysis also leads to a better understanding of the strategic importance of IS in the firm (see Table). For example, in the entrepreneurial and cognitive schools, IS may be seen as providing an information flow that supports the rationalisation of the subjectivity and intuition involved in decision-making. In other words, IS helps strategists in non-routine complex decisions that are key to formulating and re-formulating strategy. In the learning and power schools, by contrast, IS may be seen as an information flow that supports the organisation's own way of working, that is to say, IS facilitates restructuring or strategy implementation tasks. In the design, planning, positioning, culture and configuration schools, IS can be seen as information flows supporting all strategic functions and processes. Finally, in the environmental school, IS is seen with an emphasis on emergent technology, which impacts people and organisations.

Nowadays, in an increasingly complex and dynamic competitive environment, strategy implementation is becoming as important as strategy formulation. In this context, IS can facilitate organisational innovation. IS support the flow of information in all directions within the organisation (both operational and managerial); they thus facilitate organisational learning and more effective communication, coordination and control, which can lead to better individual and organisational work. Also, currently available IT (client-server systems, open standards, interoperative communications, the Internet, etc.) offers a powerful infrastructure for rapid and effective communication.

On the other hand, when managers choose a technological platform to support their firm's strategy, they should consider certain very particular features of information technology, such as technological obsolescence and immature technology. In other words, because technology changes very fast, the solution may be to adopt an emergent technology. Yet an emergent IT may be immature and incapable of optimally supporting strategy formulation and implementation. Among the technologies that are still immature are workflow (complexity) and video-conferencing (bandwidth restrictions). 


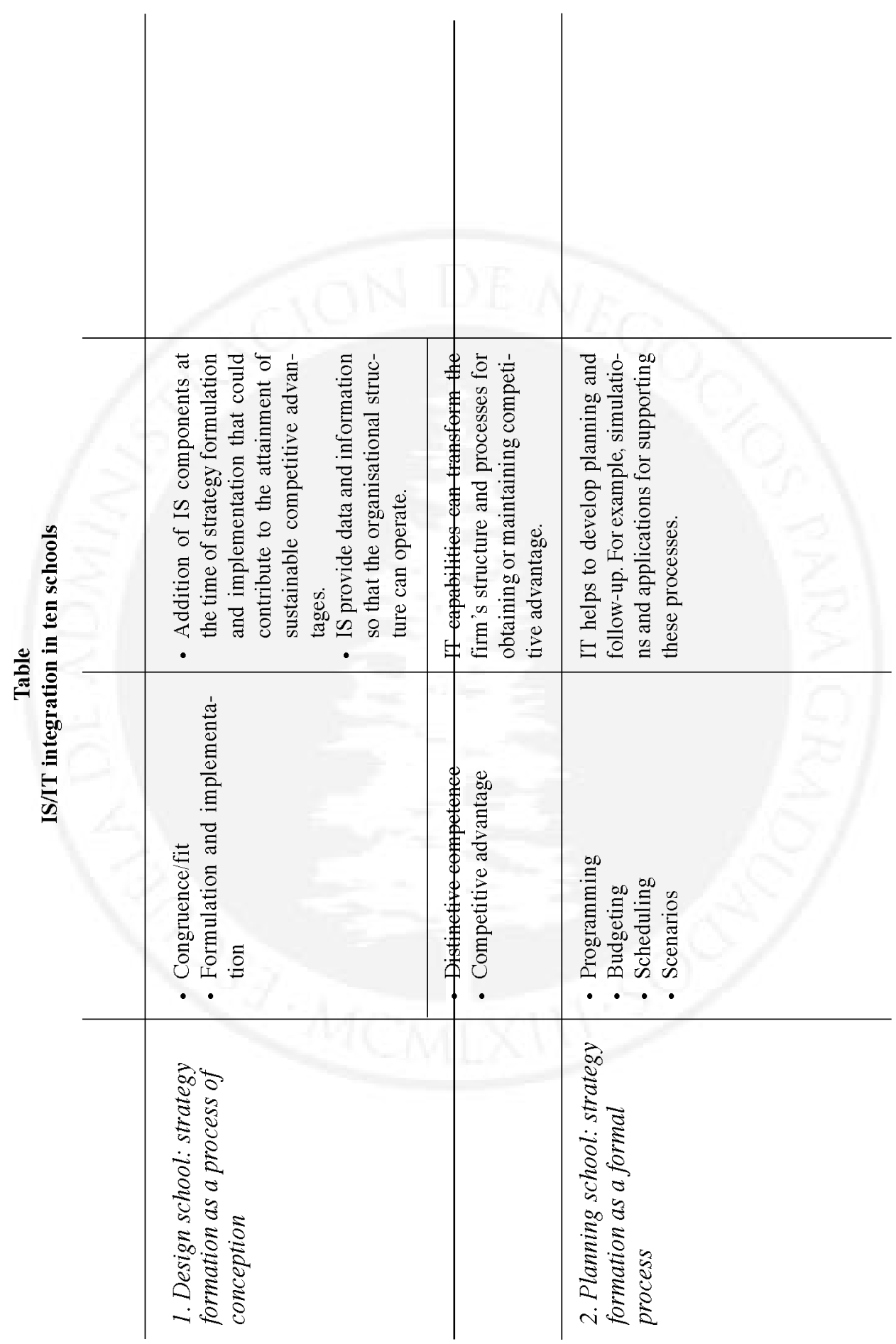

Año 8, n.. 14, junio de 2003 


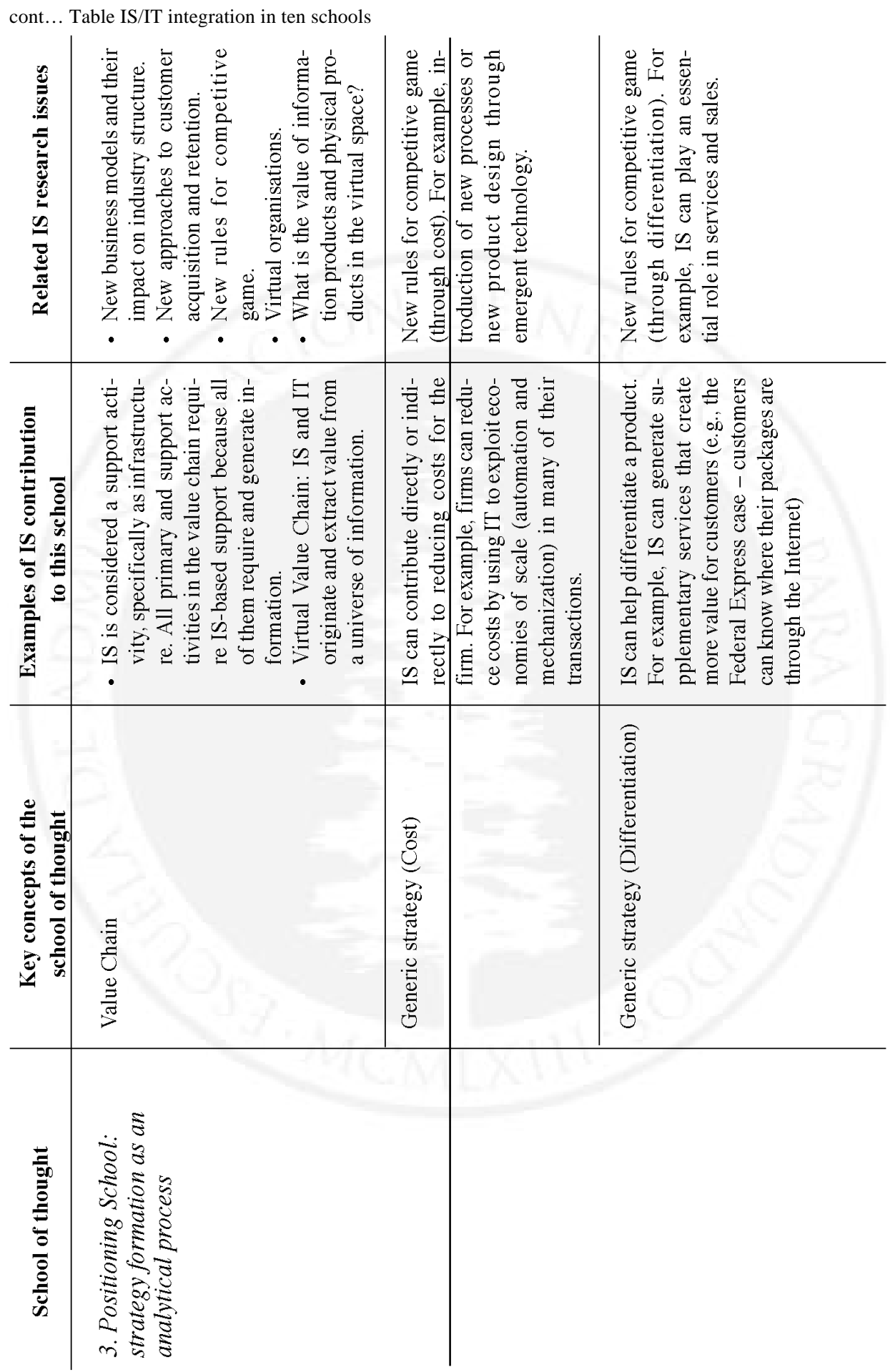


cont... Table IS/IT integration in ten schools

\begin{tabular}{|c|c|c|c|c|c|}
\hline 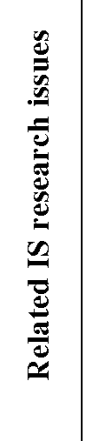 & 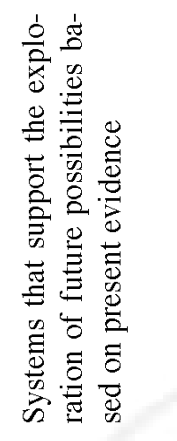 & 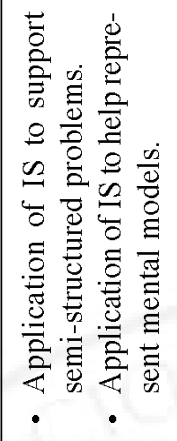 & & & 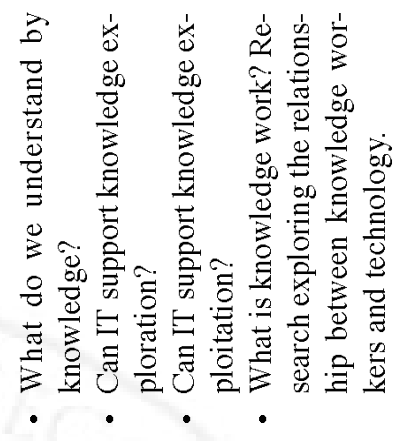 \\
\hline 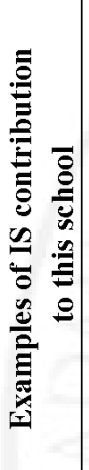 & 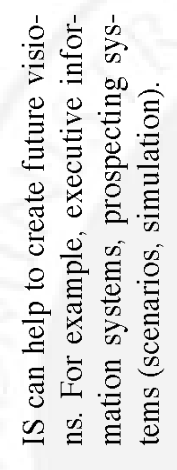 & 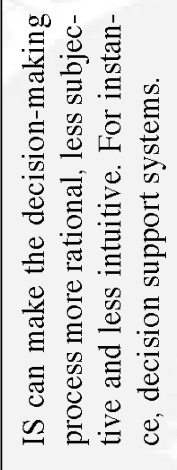 & 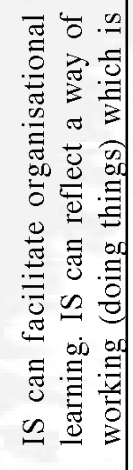 & 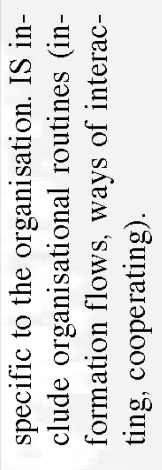 & 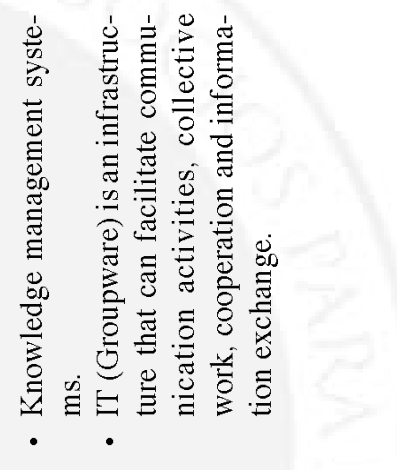 \\
\hline 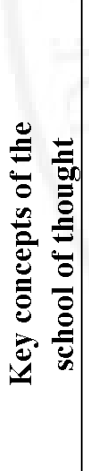 & 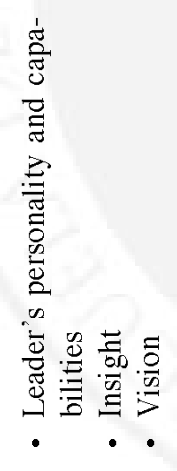 & 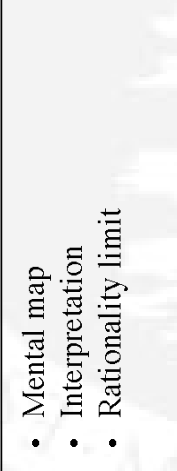 & 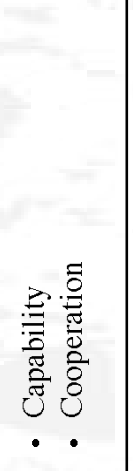 & & $\begin{array}{l}0 \\
\frac{0}{0} \\
\frac{0}{0} \\
\overline{3} \\
0 \\
0 \\
0\end{array}$ \\
\hline 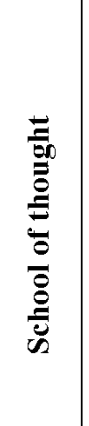 & 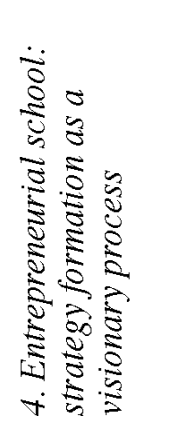 & 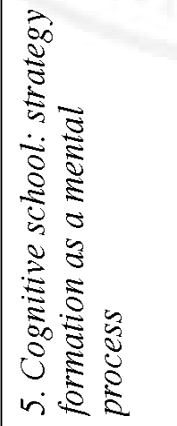 & 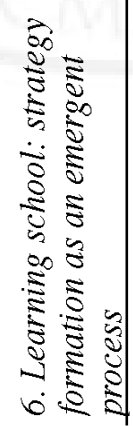 & & \\
\hline
\end{tabular}

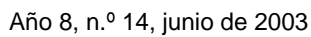




\begin{tabular}{|c|c|c|c|c|c|}
\hline 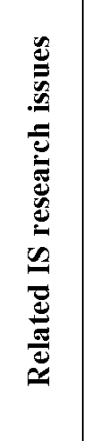 & & 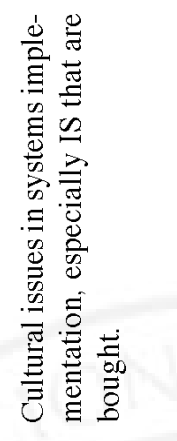 & 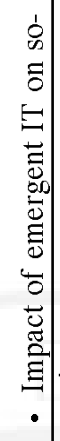 & 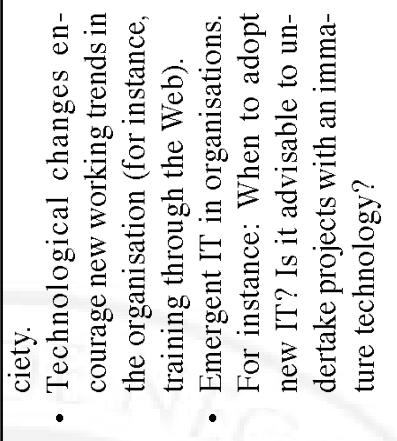 & 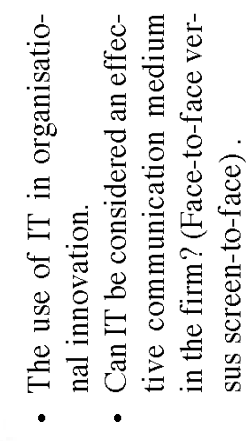 \\
\hline 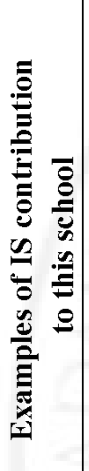 & 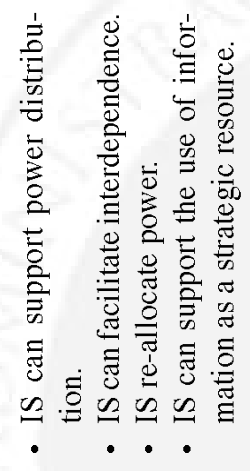 & 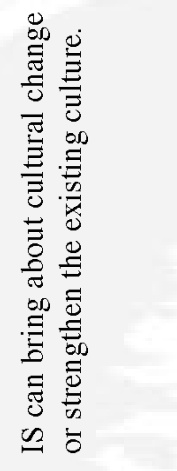 & 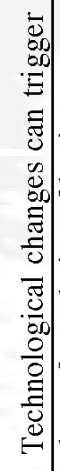 & 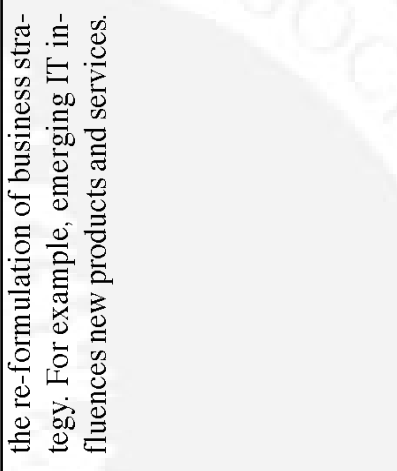 & 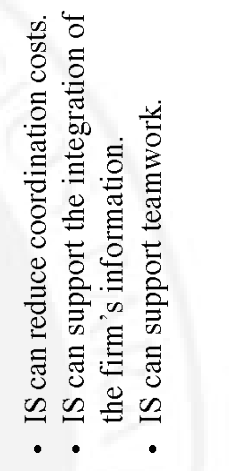 \\
\hline 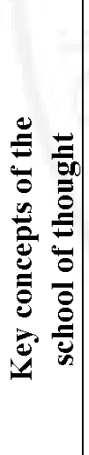 & 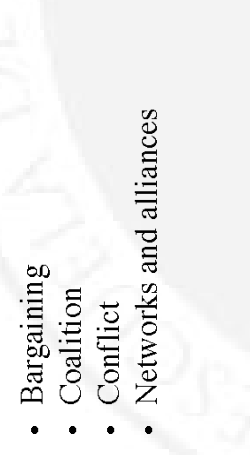 & 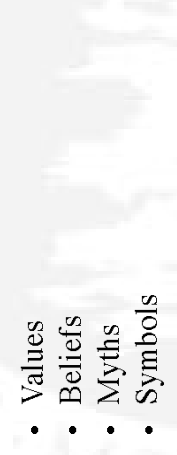 & 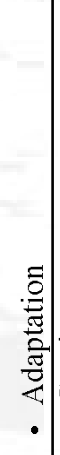 & 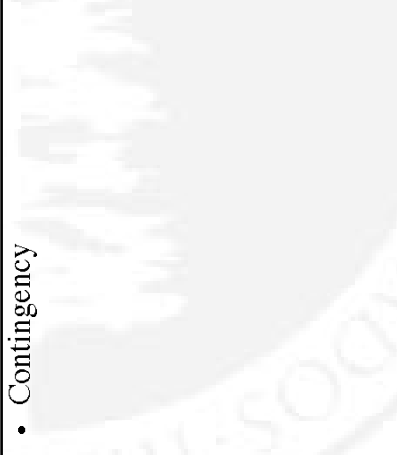 & 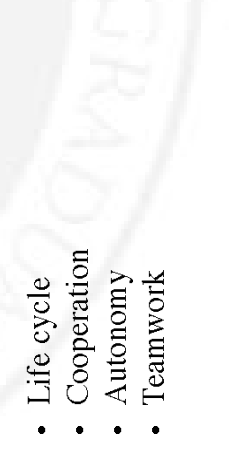 \\
\hline 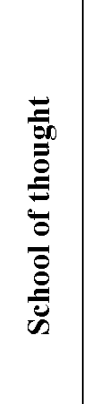 & 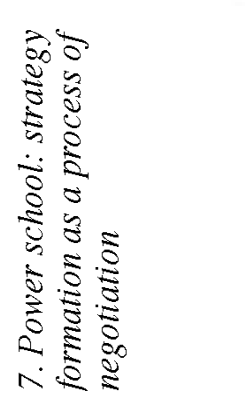 & 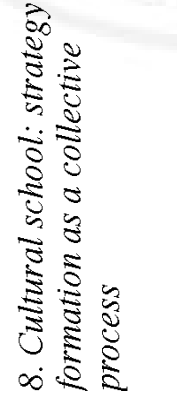 & 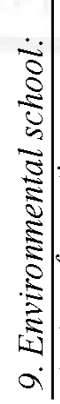 & 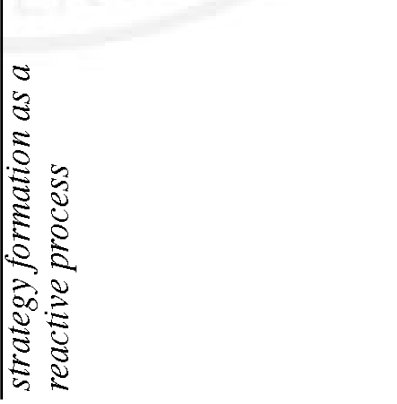 & 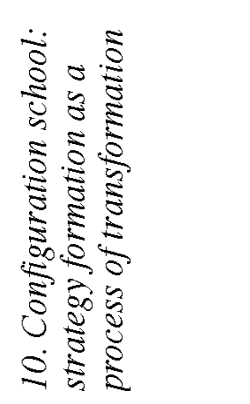 \\
\hline
\end{tabular}

Año 8, n.․ 14, junio de 2003 


\section{References}

ALLEN, Thomas J. and SCOTT MORTON, Michael S. 1994. Information Technology and the Corporation of the 1990s: Research Studies. Oxford University Press.

ALTER, Steven. 1977. A Taxonomy of Decision Support Systems. Sloan Management Review. Cambridge, Vol. 19, n. ${ }^{\circ} 1$.

ANDREU, R. and CIBORRA, C. 1996. Organisational Learning and Core Capabilities Development: The Role of IT. Journal of Strategic Information Systems. N. ${ }^{\circ}$ 5, p. 111-127.

ANDREU, R.; RICART, Joan and VALOR, Josep. 1992. Information Systems Strategic Planning: A Source of Competitive Advantage. Oxford: NCC Blackwell.

ANDREWS, K. R. 1971. The Concept of Corporate Strategy. Third Edition. Homewood, IL: Irwin.

APPLEGATE, Lynda M. 1999. In Search of New organizational Model: Lessons from the Field. In: DeSanctis, G. and Fulk, Janet (Eds.). Shaping Organization Form: Communication, Connection \& Community. Newbury Park, Ca: Sage Publications.

ARGYRIS, C. 1993. On Organizational Learning. Cambridge, M.A.: Blackwell Publishers.

BARNEY, Jay B. 1986. Organizational Culture: Can It Be a Source of Sustained Competitive Advantage? Academy of Management Review. Vol. 11, n. ${ }^{\circ}$ 3, p. 656-665.

BENJAMIN, R. I.; ROCKART, J. F.; SCOTT MORTON, M. S. and WYMAN, J. 1984.
Information Technology: A Strategic Opportunity. Sloan Management Review. Vol. 25, n. ${ }^{\circ} 3$, p. 3-10.

BRADLEY, Stephen; HAUSMAN, Jerry and NOLAN, Richard. 1993. Globalization, Technology and Competition: The Fusion of Computers and Telecommunications in the 1990s. Harvard Business School Press.

CASH, James and KNOSINSKI, B. R. 1985. Information Systems Redraw Competitive Boundaries. Harvard Business Review. March-April, p. 134-142.

CASH, James; MCFARLAN, Warren; MCKENNEY, James and APPLEGATE, Lynda. 1998. Corporate Information Systems Management: Text and Cases. Fifth Edition. Chicago: Irwin.

CHRISTENSEN, C. R.; ANDREWS, K. R. and BOWER, J. L. 1973. Business Policy: Text and Cases. Homewood, Ill: Richard D. Irwin.

DAVENPORT, Thomas H. 1994. Saving IT's Soul: Human-Centered Information Management. Harvard Business Review. Vol. 72, n. ${ }^{\circ}$ 2, p. 119-131.

DESANCTIS, G. and GALLUPE, R. Brent. 1985. Group Decision Support Systems: A New Frontier. Data Base. Winter.

EARL, J. Michael. 1996. Integrating IS and the Organization: A framework of Organization Fit. In: Earl (Ed.). Information Management: The Organizational Dimension. Oxford University Press. 
FEENY, David and IVES, Blake. 1997. IT as a Basis for Sustainable Competitive Advantage. In: Willcocks, L.; Feeny, David and Islei, Gerd (Eds.). Managing IT as a Strategic Resource. London: McGraw-Hill.

FIOL, C. M. and Lyles, M. A. 1985. Organizational Learning. Academy of Management Review. N. ${ }^{\circ} 10$, p. 803-813.

GALBRAITH, J. R. 1973. Designing Complex Organizations. Reading, Massachussetts: Addison-Wesley.

GALBRAITH, J. R. and LAWLER III, E. E. 1993. Effective Organizations: Using the New Logic of Organizing. In: Galbraith, J. R., Lawler III E.E. and Associates (Eds.). Organizing for the Future: The New Logic for Managing Complex Organizations. San Francisco: Jossey-Bass Publishers.

GRAY, P. and NUNAMAKER. 1993. Group Decision Support Systems. In: Sprague \& Watson (Eds.). Decision Support Systems: Putting Theory into Practice. Third edition. Prentice Hall International.

GOODMAN, Paul and DARR, Eric. 1998. Computer-Aid Systems and Communities: Mechanism for Organization Learning in Distribuited Environments. MIS Quarterly. December.

GORRY, G. A. and SCOTT MORTON, M. S. 1971. A Framework for Management Information Systems. Sloan Management Review. Vol. 13, n. ${ }^{\circ}$ 1, p. 55-70.

HAMEL, G. and PRAHALAD, C. K. 1994. Competing for the Future. Boston: Harvard Business School Press.

HANNAN, M. T. and FREEMAN, J. 1977. The Population Ecology of Organizations.
American Journal of Sociology. Vol. 82, n. ${ }^{\circ}$ 5, p. $929-964$.

HATCH, Mary Jo. 1997. Organization Theory: Modern, Symbolic and Postmodern Perspective. Oxford University Press.

HENDERSON, C. John and VENKATRAMAN, N. 1994. Strategic Alignment: A Model for Organizational Transformation via Information Technology. In: Allen, J. Thomas and Scott Morton, Michael (Eds.). Information Technology and the Corporation of the 1990s: Research Studies. Oxford University Press.

HUBER, G. P. 1984. Issues in the Design of Group Decision Support Systems. MIS Quarterly. N. 8, p. 195-204.

1991. Organizational Learning: The Contributing Process and the Literatures. Organization Sciences. Vol. 2, n. ${ }^{\circ}$ 1, p. 88115.

IVES, B. and OLSON, M. H. 1981. Manager or Technician: the Nature of the Information Systems Manager's Job. MIS Quarterly. Vol. 4, n. ${ }^{\circ} 4$.

IVES, B. and LEARMONTH, G. P. 1984. The Information Systems as a Competitive Weapon. Communication of the ACM. Vol. 27, n. ${ }^{\circ} 12$, p. 1193-1201.

KEEN, P. G. W. and SCOTT MORTON, M. S. 1978.Decision Support Systems: An Organizations Perspective. Reading, M.A.: Addison Wesley.

KING, W. R. 1978. Strategic Planning for Management Information Systems. MIS Quarterly. N. ${ }^{\circ}$ 2, p. 27-37. 
1996. IS and the Learning Organization. Information Systems Management. Vol. 13, n. ${ }^{\circ}$ 3, p. $78-80$.

MALONE, T. W. 1987. Modeling Coordination in Organizations and Markets. Management Science. N. ${ }^{\circ}$ 33: 1317-1332.

MARCH, J. G. and SIMON, H. A. 1958. Organizations. New York: Wiley.

MARKUS, M. Lynne. 1983. Power, Politics, and MIS Implementation. Comunnications of $A C M$. Vol. 26, n. ${ }^{\circ}$ 6, p. 430-444.

MCFARLAN, F. W. 1984. Information Technology Changes the Way You Compete. Harvard Business Review. Vol. 62, n. ${ }^{\circ}$, p. 98-113.

MEYER, J. W. and ROWAN, B. 1977. Institutionalized Organizations: Formal Structure as Myth and Ceremony. American Journal of Sociology. N. ${ }^{\circ}$ 83, p. 340-363.

MINTZBERG, Henry. 1990. Strategy Formation: Schools of Thought. In: Fredrickson (Ed.). Perspective on Strategic Management. Harper Business.

MINTZBERG, Henry; AHLSTRAND, Bruce and LAMPEL, Joseph. 1998. Strategic Safari. Prentice Hall.

MINTZBERG, H. and WATERS, J. A. 1985. Of Strategies: Deliberate and Emergent. Strategic Management Journal. July-September, p. 84-91.

SCOTT MORTON, M. S. 1971. Management Decision Systems: Computer Based Support for Decision Making. Boston: Harvard University Graduate School of Business Administration.
NOLAN, R. L. 1979. Managing the Crisis in Data Processing. Harvard Business Review. March-April.

OLSON, Margrethe. 1982. New Information Technology and Organizational Culture. MIS Quarterly. Special Issue, p. 71-92.

PARSONS, G. L. 1983. Information Technology: A New Competitive Weapon. Sloan Management Review. №. 24, p. 3-14.

PFEFFER, Jeffrey. 1992. Managing with Power: Politics and Influence in Organizations. Harvard Business School Press.

PORTER, M. E. \& MILLER, V. E. 1985. How information gives you competitive advantage. Harvard Business Review. Vol. 63, n. ${ }^{\circ}$, p. $149-160$.

PORTER, M. E. 1985. Competitive Advantage: Creating and Sustaining Superior Performance. New York: Free Press.

1980. Competitive Strategy: Techniques for Analyzing Industries and Competitors. New York: Free Press.

RAYPORT, Jeffrey and SVOKLA, John. 1995. Exploiting the Virtual Value Chain. Harvard Business Review. Nov-Dec.

ROCKART, J. F. and DELONG, D. W. 1988. Executive Support Systems: The Emergence of Top Management Computer Use. Homewood, IL: Dow Jones-Irwin.

ROCKART, J. F. 1979. Chief Executives Define their Own Data Needs. Harvard Business Review. Vol. 57, $\mathrm{n}^{\circ}$ 2, p. 81-93.

SCHEIN, Edgar H. 1997. Organizational Culture and Leadership. Second Edition. San Francisco: Jossey-Bass Publishers. 
SEEN, James. 1992. The Myths of Strategic Information Systems: What Defines True Competitive Advantage? Journal of Information Systems Management. Summer.

SIMON, H. A. 1997. Administrative Behaviour: A study of Decision Making Processes in Administrative Organizations. Fourth Edition. New York: The Free Press.

SPRAGUE and WATSON. 1993. The Components of an Architecture for DSS. In: Sprague \& Watson (Eds.). Decision Support Systems: Putting Theory into Practice. Third edition. Prentice Hall International.

SPRAGUE, Ralph H. 1980. A Framework for the Development of Decision Support Systems. MIS Quarterly. Vol. 4, n. ${ }^{\circ}$.
STEINER, G. A. 1979. Strategic Planning: What Every Manager Must Know. New York: The Free Press.

TURBAN, Efraim. 1988. Decision Support and Expert Systems: Managerial Perspectives. McMillan Pub. Co.

WATSON, Hugh; RAINER, Kelly and KOH, Chang. 1991. Executive Information: A Framework for Development and a Survey of Current Practices. MIS Quarterly. Vol. 15, n. $^{\circ} 1$.

WISEMAN, Charles. 1988. Strategic Information Systems. Homewood, Illinois: Irwin.

ZUBOFF, S. 1988. In the Age of the Smart Machine. New York: Basic Books. 